\title{
Секвенирование вироидов
}

\section{H.В. Шацкая (iD凶}

Аннотация: Вироиды представляют собой небольшие патогенные РНК-молекулы длиной от 246 до 467 нуклеотидов, состоящие из одноцепочечной кольцевой РНК, без капсида и последовательностей, кодирующих белок. Вироиды проникают в растения и используют систему хозяина для размножения. Они индуцируют структурные и физиологические изменения в клетках хозяйского организма, которые впоследствии приводят к развитию различных заболеваний. Выявление вироидов непростая задача, с которой довольно успешно справляется NGS-секвенирование. C 2009 г. технологию NGS начали использовать в нескольких областях вирусологии растений, включая секвенирование геномов вироидов, открытие новых видов и определение уже известных. Также NGS-секвенирование может быть использовано в экологии, эпидемиологии, изучении репликации и транскрипции вироидов. В вирусологии растений данная технология наиболее удобна для определения уже известных и новых вироидов в инфицированных растениях. Предполагается, что NGS будет играть значительную роль во многих исследованиях по вирусологии растений и в дальнейшем.

Ключевые слова: секвенирование нового поколения; вироиды; патогены; биобезопасность.

Благодарности: Исследование выполнено при финансовой поддержке РНФ, проект 20-46-07001.

Для цитирования: Шацкая Н.В. Секвенирование вироидов. Письмав Вавиловский журналгенетикии селекции. 2021;7(1):17-22. DOI 10.18699/ LettersVJ2021-7-03

\section{Review}

\section{Methods of viroid sequencing}

\section{N.V. Shatskaya (D)凶}

Abstract: Viroids are small, single-stranded pathogenic RNA-molecules from 246 to $467 \mathrm{bp}$, circular, non-encapsulated and they do not code proteins. Viroids penetrate to plants and depend on host enzymes for their replication. They induce structural and physiological changes in host plant that become to diseases. Viroids detection is not so simple problem, and NGS-sequencing can help to solve it. In 2009, NGS technologies began to be applied to several areas of plant virology including virus/viroid genome sequencing, discovery and detection, ecology and epidemiology, replication and transcription. Identification and characterization of known and unknown viroid in infected plants are currently among the most successful applications of these technologies. It is expected that NGS will play very significant role in plant virology.

Key words: next generation sequencing; viroids; pathogens; biosafety.

For citation: Shatskaya N.V. Methods of viroid sequencing. Pisma v Vavilovskii Zhurnal Genetiki i Selektsii = Letters to Vavilov Journal of Genetics and Breeding. 2021;7(1):17-22. DOI 10.18699/LettersVJ2021-7-03 (in Russian)

Со времен открытия вироиды остаются одними из самых загадочных биологических молекул и являются самыми маленькими из известных инфекционных РНК. Вироиды представляют собой РНК-репликоны длиной от 246 до 467 нуклеотидов, состоящие из одноцепочечной кольцевой РНК, в которой отсутствуют последовательности, кодирующие белок (Katsarou et al., 2015). Первый вироид открыт Теодором Динером в 1967 г. и впоследствии назван вироидом веретеновидности клубней картофеля (PSTVd) (Diener, Raymer,
1967). Вироиды подразделяют на два семейства. Вироиды семейства Pospiviroidae реплицируются в ядре по ассиметричному кольцевому механизму. Большинство членов этого семейства имеют структуру, состоящую из пяти доменов: терминального левого, патогенного, центрального, вариабельного и терминального правого. Выделяют пять родов: Pospiviroid (potato spindle tuber viroid, PSTVd), Hostuviroid (hop stunt viroid, HSVd), Cocadviroid (coconut cadang-cadang viroid, CCCVd), Apscaviroid (apple scar skin viroid, ASSVd) и 
Coleviroid (coleus blumei viroid 1, CbVd-1).

Вироиды другого семейства, Avsunviroidae, - небольшая группа, состоящая из трех родов: Avsunviroid (avocado sunblotch viroid, ASBVd), Pelamoviroid (peach latent mosaic viroid, PLMVd) и Elaviroid (eggplant latent viroid, ELVd). Типичный представитель этого семейства - PLMVd, вироид латентной мозаики персика, кодирует саморазрезающиеся PHК (рибозимы типа hammerhead), которые реплицируются в хлоропластах через симметричный кольцевой механизм (Oliver, Fuchs, 2011).

\section{Симптомы заражения и методы определения}

Вироиды могут индуцировать структурные и физиологические изменения в клетках хозяйского организма (Di Serio et al., 2013), которые впоследствии приводят к развитию различных заболеваний (Flores et al., 2012). Симптомы инфицирования вироидами могут варьировать по степени проявления. Иногда эти проявления могут быть очень слабыми. Заражение вироидами может быть выражено только в отдельных органах растения или проходить бессимптомно, как в случае диких растений (Flores et al., 2005). Надо отметить, что вироиды переносятся механически и для своего размножения используют транскрипционный механизм хозяина. Репликация вироидов происходит по симметричному или ассиметричному круговому циклу и обусловлена активностью ДНК-зависимой РНК-полимеразы хозяина, которая использует РНК вироидов как матрицу для создания новых копий кольцевой РНК через промежуточную форму двуцепочечных PHК (дцРНК) (Flores et al., 2011). Производные дцРНК вироидов также реплицируются при помощи хозяйской РНК-зависимой РНК-полимеразы, включенной в механизм РНК-сайленсинга растения-хозяина (Di Serio et al., 2010).

В инфицированной вироидом клетке в процессе репликации происходят изменения в нуклеотидной последовательности вироидных потомков. Образовавшиеся популяции полиморфных молекул РНК могут служить источником адаптации к новым хозяевам и новым условиям жизненного цикла. Таким образом, после инфицирования каждый вариант вироида способен продуцировать свою популяционную динамику в хозяйском растении. Эта концепция носит название квазивидов и впервые предложена в 1993 г. (Eigen, 1993). Чрезвычайная изменчивость нуклеотидных последовательностей вироидов характеризует их как наиболее быстро развивающуюся из известных биологических систем (Matousek, 2002).

Как отдельный класс патогенов, вироиды отчетливо отличаются от вирусов. Хотя вироиды и демонстрируют некоторые структурные и биологические сходства с вирусом гепатита дельта, последний в пять раз больше и кодирует два белка с одной рамки считывания (Flores et al., 2016). Некоторые вироиды и вирусы могут иметь бессимптомное проявление в организме хозяина. Однако эти латентные агенты могут быть патогенами для других хозяев. Существующие специфические методы, такие как ПЦР, очень чувствительны, но детектируют только известные вироиды или вирусы. Эти методы не способны показать плохо охарактеризованные или сильно вариабельные вироиды. Более того, часто хозяйское растение может быть заражено несколькими патогенами, как известными, так и экзотическими, которые стандартные скрининговые методы не могут обнаружить. В данном случае может быть полезно секвенирование нового поколения (next generation sequence, NGS) для выявления, исследования и сертификации патогенов.

\section{Выбор платформы для секвенирования}

Значительный прогресс в технологии секвенирования произошел в последние два десятилетия и привел к развитию новых подходов выявления и идентификации вироидов. Данные подходы относят к метагеномике, при которой производится полное секвенирование суммарной ДНК в образцах зараженных растений с помощью NGS с последующей идентификацией патогенов биоинформатическими методами. Поскольку обычно вироиды присутствуют в растениях в низких концентрациях и весьма вариабельны, их обнаружение - сложная задача для многих лабораторий, занимающихся патологией растений. Это является одной из причин того, что с момента открытия за 40 лет идентифицированы менее 40 видов вироидов из двух семейств. Платформа NGS появилась в начале 2000 г., и ее использование с 2004 г. изменило подход к исследованиям во многих областях, включая растительную вирусологию.

NGS-технологии можно разделить на две группы: первая - с короткими прочтениями (100-600 п.н.) и высокой точностью, вторая - с длинными прочтениями $\left(900 \times 10^{3}\right.$ п.н.) и большим количеством ошибок. Это привело к разным подходам приготовления образцов, секвенирования, детекции и анализа данных (Васильев, 2014) (табл. 1). Наиболее часто используют короткие прочтения, поскольку этот вариант дешевле и точность прочтения выше. Однако при коротких прочтениях имеется ограничение в возможности прочтения сложных участков с повторами или последовательности гетерозигот, для которых больше подходят технологии с длинными прочтениями. Illumina, lon Torrent, 454 Life Science, SOLID - платформы, которые созданы для коротких прочтений (см. табл. 1). Среди приборов с длинными прочтениями - MinION, который использует технологию нанопорового секвенирования, и РасВіо с детекцией молекул в реальном времени.

\section{Выбор подхода секвенирования вироидной РНК}

Поскольку вироиды содержат РНК, которая не кодирует полезные им в жизненном цикле белки, знание структуры, помогающей вироидам адаптироваться, важно как для понимания взаимодействия хозяина и патогена, так и самого цикла размножения вироида. С момента открытия вироидов их молекулярная структура оставалась неизвестной, поскольку они не проявляли физически узнаваемых характеристик, таких как клеточная структура у бактерий или белки у вирусов. Первая структура молекулы вироида получена для PSTVd с помощью секвенирования в геле и сборки перекрывающихся последовательностей (Gross et al., 1978). Характеризация вироидных PHK с помощью NGS выполнена в 2009 г. у винограда и персиков (Di Serio et al., 2009; Navarro et al., 2009). С этого времени NGS активно используют для анализа взаимодействий вироидов и хозяев у травянистых 
Таблица 1. Платформы для NGS (Barba et al., 2014)

\begin{tabular}{|c|c|c|c|c|c|c|}
\hline $\begin{array}{l}\text { Прибор } \\
\text { (производитель) }\end{array}$ & $\begin{array}{l}\text { Метод ампли- } \\
\text { фикации }\end{array}$ & Метод детекции & $\begin{array}{l}\text { Длина про- } \\
\text { чтения, п.н. }\end{array}$ & $\begin{array}{l}\text { Скорость } \\
\text { секвенирова- } \\
\text { ния, п.н./ч }\end{array}$ & $\begin{array}{l}\text { Точ- } \\
\text { ность, } \\
\%\end{array}$ & $\begin{array}{l}\text { Мисматчи, инсерции, } \\
\text { делеции }\end{array}$ \\
\hline $\begin{array}{l}454 \text { Life Science } \\
\text { (Roche) }\end{array}$ & $\begin{array}{l}\text { Эмульсионная } \\
\text { ПЦР }\end{array}$ & $\begin{array}{l}\text { Пиросеквениро- } \\
\text { вание }\end{array}$ & $400-700$ & 13 млн п.н. & 99.9 & $\begin{array}{l}\text { 0.10/0.3/0.02 } \\
\text { (Archer et al., 2012) }\end{array}$ \\
\hline Illumina (Illumina) & $\begin{array}{l}\text { Мостиковая } \\
\text { ПЦР }\end{array}$ & $\begin{array}{l}\text { Обратимое терми- } \\
\text { нирование }\end{array}$ & $100-300$ & 25 млн п.н. & 99.9 & $\begin{array}{l}0.12 / 0.004 / 0.006 \\
\text { (Archer et al., 2012) }\end{array}$ \\
\hline $\begin{array}{l}\text { SOLiD (Life } \\
\text { Technologies) }\end{array}$ & $\begin{array}{l}\text { Эмульсионная } \\
\text { ПЦР }\end{array}$ & Лигирование & $75-85$ & $\begin{array}{l}21-28 \\
\text { млн п.н. }\end{array}$ & 99.9 & $\begin{array}{l}\text { Ошибка больше, чем } \\
\text { в Illumina (Meyerand, } \\
\text { Kircher, 2010) }\end{array}$ \\
\hline $\begin{array}{l}\text { PacBio (Pacific } \\
\text { Biosciences) }\end{array}$ & $\begin{array}{l}\text { Без амплифи- } \\
\text { кации }\end{array}$ & $\begin{array}{l}\text { Флуоресцентно ме- } \\
\text { ченые нуклеотиды }\end{array}$ & $\begin{array}{l}15000- \\
30000\end{array}$ & $\begin{array}{l}\text { 50-115 } \\
\text { млн п.н. }\end{array}$ & 95 & $\begin{array}{l}1,2,12 \\
\text { (Carniero et al., 2012) }\end{array}$ \\
\hline $\begin{array}{l}\text { Ion Torrent (Life } \\
\text { Technologies) }\end{array}$ & $\begin{array}{l}\text { Эмульсионная } \\
\text { ПЦР }\end{array}$ & $\begin{array}{l}\text { Детекция высво- } \\
\text { бождаемых ионов }\end{array}$ & $100-400$ & $\begin{array}{l}100 \text { млн п.н. - } \\
64 \text { млрд п.н. }\end{array}$ & 99 & $\begin{array}{l}\text { Инсерции = 0.06, } \\
\text { инсерции + } \\
\text { делеции = } 1.38 \\
\text { (Bragg et al., 2013) }\end{array}$ \\
\hline $\begin{array}{l}\text { MinION (Oxford } \\
\text { Nanopore } \\
\text { Technologies) }\end{array}$ & $\begin{array}{l}\text { Нанопоровое } \\
\text { секвенирова- } \\
\text { ние }\end{array}$ & $\begin{array}{l}\text { Сила тока при про- } \\
\text { хождении через } \\
\text { пору }\end{array}$ & $900 \times 10^{3}$ & & $90-95$ & $5-10 \%$ \\
\hline
\end{tabular}

Таблица 2. Новые вироиды, определенные с помощью NGS

\begin{tabular}{lllll}
\hline Способ обогащения & Платформа NGS & $\begin{array}{l}\text { Количество опреде- } \\
\text { ленных вироидов }\end{array}$ & Хозяин & Источник литературы \\
\hline Тотальная PHK & 454 & 3 & Виноград & Al Rwahnih et al., 2009 \\
\hline $\begin{array}{l}\text { PHК без рибосомной } \\
\text { фракции }\end{array}$ & Illumina & 4 & Виноград & Poojari et al., 2013 \\
\hline Двуцепочечная PHK & 454 & 3 & Виноград & Al Rwahnih et al., 2009 \\
\hline Малые PHK & Illumina & 1 & Томат & Li et al., 2012 \\
\hline Малые PHK & Illumina & 2 & Виноград & $\begin{array}{l}\text { Giampetruzzi et al., 2012; Wu et al., 2012; } \\
\text { Малые PHK }\end{array}$ \\
\hline Малые PHK & Illumina & 2 & Мандарин & Loconsole et al., 2012 \\
\hline
\end{tabular}

и древесных растений (Hadidi et al., 2016). Сочетание биоинформатических подходов со сборкой контигов и поиском гомологов вироидных последовательностей в базах данных NGS библиотек малых PHК широко и эффективно применяют для идентификации известных и новых вироидов. Разработанные в последнее время алгоритмы позволяют производить независимую от гомологии идентификацию новых вироидов или вироид-подобных РНК, например вироидов яблок или винограда (Wu et al., 2012; Zhang et al., 2014).

Также необходимо отметить такую проблему, как гетерогенность вироидов. Например, для вироида экзокортиса цитрусовых (CEVd) секвенировано 17 вариантов, которые делят на два класса, отличающихся как минимум на 26 нуклеотидов и с вариациями по длине от 370 до 375 нуклеотидов. Степень проявления симптомов у растения во время заражения может сильно варьировать. Один штамм вироида может индуцировать несколько явных и серьезных симптомов, в то время как другой штамм индуцирует незначительные проявления (Visvader, Symons, 1985). Варианты секвенирования PSTVd, с отличиями в несколько нуклеотидов (около 40 разных вариантов длиной 359-360 п.н.), были разделены на штаммы по симптомам проявления: мягкие, средние, обычные и летальные (Herold et al., 1992; Lakshman, Tavantzis, 1993).

Для увеличения выхода вироидной РНК возможны несколько стратегий обогащения и специфичного секвенирования вироидов. Один из вариантов - избавление от хозяйской рибосомальной PHK (Poojari et al., 2013; Zhang et al., 2014).

Например, при анализе полной последовательности РНК растений винограда Syrah использована платформа 454 Life Sciences и обнаружены последовательности HSVd (hot stunt viroid - вироид, замедляющий рост хмеля), GYSVd (grapevine yellow speckle viroid - желтый крапчатый вироид винограда) 


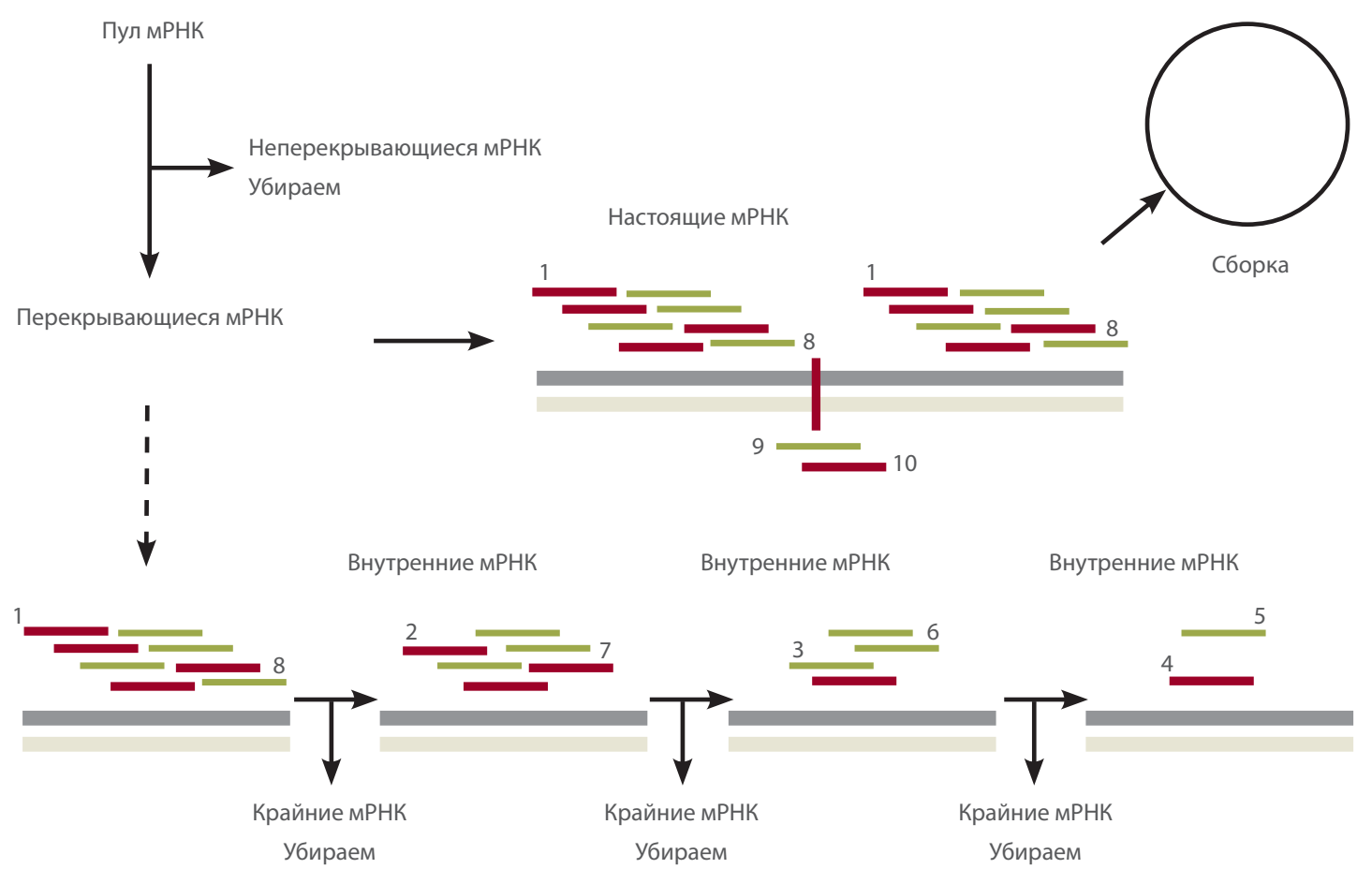

Ключевые моменты компьютерных алгоритмов, которые фильтруют перекрывающиеся малые PHK (PFOR)

и AGVd (australian grapevine viroid - австралийский вироид винограда). В этом исследовании присутствие известных вироидов в образце может быть подтверждено поиском гомологичных последовательностей при помощи таких платформ, как VirFind, VirusDetect или Virtool (Ho, Tzanetakis, 2014; Rott et al., 2017; Zheng et al., 2017a).

Поскольку дцРНК синтезируется вирусами и вироидами и не производится самим растением, то секвенирование общей дцРНК сильно увеличивает число последовательностей, специфичных для вироидов. Например, сравнение глубокого секвенирования общей РНК и дцРНК растений показало, что число ридов вируса возросло с 2 до 53\% после обогащения по дцРHK (Al Rwahnih et al., 2009) (табл. 2). Более того, дцРНК-интермедиаты вироидов, или сателлитные РНК, также процессируются в малые интерферирующие РНК (миРНК) в растениях.

Инфицирование вироидом запускает продукцию большого количества производных перекрывающихся миРНК, которые покрывают геном с высокой плотностью (Di Serio et al., 2009) и могут составлять до $30 \%$ общих РНК, выделенных из растения. Вироидные и вирусные миРНК являются продуктами ответа иммунной системы хозяина на инфекцию и имеют специфический профиль распределения по размерам в различных видах благодаря Dicer-подобным белкам. При обогащении и секвенировании миРНК анализируют последовательность с помощью компьютерных алгоритмов, которые фильтруют перекрывающиеся малые PHK (filtering of overlapping small RNAs, PFOR) (Wu et al., 2012, 2015) (рисунок). Вироидные миРНК не могут быть собраны в полный геном вироида с помощью обычных алгоритмов сборки, таких как Velvet, в силу высокой гетерогенности популяции виро- идов. Алгоритм PFOR оставляет вироидные миРНК, подходящие для сборки генома, прогрессивно удаляя миРНК, которые не перекрываются или перекрываются, но не могут быть собраны точно с повторяющимися РНК. Последние обновления этого алгоритма значительно увеличили производительность с помощью изменений в программе на стадии фильтрации, которая занимает более 90\% времени (Zhang et al., 2014). Новый вироид - латентный вироид винограда (grapevine latent viroid, GLVd) - идентифицирован с помощью такого подхода.

\section{Изменения в транскриптоме \\ при инфицировании вироидами}

Чтобы понимать взаимодействие хозяйского растения и вироида, изучают транскриптом растений и обнаруживают изменения в экспрессии генов, участвующих в фотосинтезе, структуре клеточной стенки, РНК-регуляции, биосинтезе гормонов, метаболизме белков и прочих ответах на стресс, который вызывает вироид. В основном эти данные относятся к семейству Pospiviroidae (Kappagantu et al., 2017; Xia et al., 2017; Zheng et al., 2017b). Например, изучение транскриптома огурца, инфицированного двумя вариантами HSVd, показало, что заражение вироидом ингибирует фотосинтез, нарушает гормональный гомеостаз и запускает основные защитные механизмы и экспрессию генов, кодирующих РНК-зависимую РНК-полимеразу (Xia et al., 2017). Листья хмеля, инфицированные HSVd, продемонстрировали основное отличие в дифференциальной экспрессии генов, которые отвечают за защиту, и генов, участвующих в липидном и терпеноидном метаболизмах (Kappagantu et al., 2017). При полном анализе транскриптома растений хмеля, 
инфицированных CBCVd, выявлено массивное изменение активности около 2000 генов, включая генов, ответственных у растения за иммунный ответ, фитогормональные сигнальные пути, фотосинтез, метаболизм пигментов, белков и сахаров (Mishra et al., 2018). Наиболее часто для исследований берут листья, но для секвенирования РНК томатов, зараженных двумя вариантами веретеновидности клубней картофеля - слабым и обычным, использовали корни растений. Результаты показали дифференциальную экспрессию генов, связанных с клеточной стенкой. На ранних этапах инфицирования их экспрессия была подавлена, а на поздних стадиях количество генов с возросшей экспрессией значительно увеличилось. Также обнаружено влияние на экспрессию генов, связанных с биосинтезом и сигнальными путями ауксина и цитокинов, которые критичны для развития латеральных корней. При сравнении двух вариантов инфекции выявлено, что обычный вариант вироида индуцирует транскрипционные изменения сильнее, чем слабый вариант, особенно на поздних стадиях инфицирования. Таким образом, инфицирование патогеном провоцирует ответ иммунной системы хозяина (Góra-Sochacka et al., 2019).

\section{Заключение}

NGS является эффективным инструментом метагеномики растений, диагностики и идентификации новых вироидов. Также NGS-технологии - мощный способ решения вопросов, связанных с карантином растений, требующих быстрой и аккуратной идентификации вироидов и вирусов в образцах. Исследование вирома является важным для биобезопасности, так как многие вирусы и вироиды не обладают морфологическими эффектами, но в то же время быстрая изменчивость делает их источником разных угроз (Kochetov et al., 2017; Pooggin, 2018; Takahashi et al., 2019).

\section{Список литературы / References}

Васильев Г.В. Геномика. Вавиловский журнал генетики и селекции. 2014;18(1):158-165.

[Vasil'ev G.V. Genomics. Vavilovskii Zhurnal Genetiki i Selektsii = Vavilov Journal of Genetics and Breeding. 2014;18(1):158-165. (in Russian)]

Barba M., Czosnek H., Hadidi A. Historical perspective, development and applications of next-generation sequencing in plant virology. Viruses. 2014;6:106-136. DOI 10.3390/v6010106.

Di Serio F., De Stradis A., Delgado S., Flores R., Navarro B. Cytopathic effects incited by viroid RNAs and putative underlying mechanisms. Front Plant Sci. 2013;3:288. DOI 10.3389/fpls.2012.00288.

Di Serio F., Gisel A., Navarro B., Delgado S., Martinez de Alba A.E., Donvito G., Flores R. Deep sequencing of the small RNAs derived from two symptomatic variants of a chloroplastic viroid: implications for their genesis and for pathogenesis. PLoS One. 2009;4:e7539. DOI 10.1371/ journal.pone.0007539.

Di Serio F., Martínez de Alba A.E., Navarro B., Gisel A., Flores R. RNA-dependent RNA polymerase 6 delays accumulation and precludes meristem invasion of a nuclearreplicating viroid. J Virol. 2010;84:24772489. DOI 10.1128/JVI.02336-09.

Diener T.O., Raymer W.B., Potato spindle tuber virus: A plant virus with properties of a free nucleic acid. Science. 1967;158:378-381. DOI 10.1126/science.158.3799.378.

Eigen M. The origin of genetic information: Viruses as models. Gene. 1993;135:37-47. DOI 10.1016/0378-1119(93)90047-7.

Flores R., Grubb D., Elleuch A., Nohales M.Á., Delgado S., Gago S. Rolling-circle replication of viroids, viroid-like satellite RNAs and hepatitis delta virus: variations on a theme. RNA Biol. 2011;8:200-206. DOI 10.4161/rna.8.2.14238.

Flores R., Serra P., Minoia S., Di Serio F., Navarro B. Viroids: from genotype to phenotype just relying on RNA sequence and structural motifs. Front Microbiol. 2012;3:217. DOI 10.3389/fmicb.2012.00217.

Flores R., Hernández C., Martínez de Alba A.E., Daròs J.-A., Di Serio F. Viroids and viroid-host interactions. Annu. Rev. Phytopathol. 2005;43:117-139. DOI 10.1146/annurev.phyto.43.040204.140243.

Flores R., Owens R.A., Taylor J. Pathogenesis by subviral agents: Viroids and hepatitis delta virus. Curr. Opin. Virol. 2016;17:87-94. DOI 10.1016/j.coviro.2016.01.022

Giampetruzzi A., Roumi V., Roberto R., Malossini U., Yoshikawa N. A new grapevine virus discovered by deep sequencing of virus- and viroidderived small RNAs in Cv Pinot gris. Virus Res. 2012;163:262-268. DOI 10.1016/j.virusres.2011.10.010.

Góra-Sochacka A., Wiesyk A., Fogtman A., Lirski M., Zagórski-Ostoja W. Root transcriptomic analysis reveals global changes induced by systemic infection of Solanum lycopersicum with mild and severe variants of potato spindle tuber viroid. Viruses. 2019;11:992. DOI 10.3390/v11110992.

Gross H.J., Domdey H., Lossow C., Jank P., Raba M., Alberty H., Sänger H.L. Nucleotide sequence and secondary structure of potato spindle tuber viroid. Nature. 1978;273:203-208. DOI 10.1038/273203a0.

Hadidi A., Flores R., Candresse T., Barba M. Next-generation sequencing and genome editing in plant virology. Front Microbiol. 2016;7:1325. DOI 10.3389/fmicb.2016.01325.

Herold T., Haas B., Singh R.P., Boucher A., Sänger H.L. Sequence analysis of five new field isolates demonstrates that the chain length of potato spindle tuber viroid (PSTVd) is not strictly conserved but as variable as in other viroids. Plant Mol. Biol. 1992;19:329-333. DOI 10.1007/BF00027356.

Ho T., Tzanetakis I.E. Development of a virus detection and discovery pipeline using next generation sequencing. Virology. 2014;471-473; 54-60. DOI 10.1016/j.virol.2014.09.019.

Kappagantu M., Bullock J.M., Nelson M.E., Eastwell K.C. Hop stunt viroid: Effect on host (Humulus lupulus) transcriptome and its interactions with hop powdery mildew (Podospheara macularis). Mol. Plant-Microbe Interact. 2017;30:842-851. DOI 10.1094/ MPMI-03-17-0071-R.

Katsarou K., Rao A.L., Tsagris M., Kalantidis K. Infectious long non-coding RNAs. Biochimie. 2015;117:37-47. DOI 10.1016/j.biochi.2015.05.005.

Kochetov A.V., Glagoleva A.Y., Strygina K.V., Khlestkina E.K., Gerasimova S.V., Ibragimova S.M., Shatskaya N.V., Vasilyev G.V., Afonnikov D.A., Shmakov N.A., Antonova O.Y., Gavrilenko T.A., Alpatyeva N.V., Khiutti A., Afanasenko O.S. Differential expression of NBS-LRR encoding genes in the root transcriptomes of two Solanum phureja genotypes with contrasting resistance to Globodera rostochiensis. BMC Plant Biology. 2017;17(251):41-50. DOI 10.1186/s12870-017-1193-1.

Lakshman D.K., Tavantzis S.M. Primary and secondary structure of a 360-nucleotide isolate of potatospindle tuber viroid. Arch. Virol. 1993;128:319-331. DOI 10.1007/BF01309442.

Li R., Gao S., Hernandez A.G., Wechter W.P., Fei Z., Ling K.S. Deep sequencing of small RNAs in tomato for virus and viroid identification and strain differentiaton. Plos One. 2012;7:e37127. DOI 10.1371/journal.pone.0037127.

Loconsole G., Onelge N., Potere O., Giampetruzzi A., Bozan O. Identification and characterization of Citrus yellow vein clearing virus, a putative new member of the genus Mandarivirus. Phytopathol. 2012;102:1168-1175. DOI 10.1094/PHYTO-06-12-0140-R.

MatousekJ.Viroids: Sequence Variability and Evolution of Pathogenic RNA. Plant Protection Science. 2002;38:173-176. DOI 10.17221/10348-PPS.

Mishra A.K., Kumar A., Mishra D., Nath V.S., Jakše J., Kocábek T., Killi U.K., Morina F., Matoušek J. Genome-wide transcriptomic analysis reveals insights into the response to citrus bark cracking viroid (CBCVd) in hop (Humulus lupulus L.). Viruses. 2018;10:570. DOI 10.3390/v10100570.

Navarro B., PantaleoV., Gisel A., Moxon S., DalmayT., Bisztray G., Di Serio F., Burgyán J. Deep sequencing of viroid-derived small RNAs from grapevine provides new insights on the role of RNA silencing in plantviroid interaction. PLoS One. 2009;4:e7686. DOI 10.1371/ journal.pone.0007686.

Oliver J.E., Fuchs M.F. Tolerance and resistance to viruses and their vectors in Vitis sp.: A virologist's perspective of the literature. Am J Enol Vitic. 2011;62:438-451. DOI 10.5344/ajev.2011.11036.

Pooggin M.M. Small RNA-Omics for Plant Virus Identification, Virome Reconstruction, and Antiviral Defense Characterization. Front Microbiol. 
2018;9:2779. DOI 10.3389/fmicb.2018.02779.

Poojari S., Alabi O.J., Fofanov V.Y., Naidu R.A. A leafhopper-transmissible DNA virus with novel evolutionary lineage in the family Geminiviridae implicated in grapevine redleaf disease by next-generation sequencing. PLoS One. 2013;8:e64194. DOI 10.1371/journal. pone.0064194.

Rott M., Xiang Y., Boyes I., Belton M., Saeed H., Kesanakurti P., Hayes S., Lawrence T., Birch C., Bhagwat B., Rast H. Application of next generation sequencing for diagnostic testing of tree fruit viruses and viroids. Plant Dis. 2017;101:1489-1149. DOI 10.1094/PDIS-03-17-0306-RE.

Rwahnih M., Daubert S., Golino D., Rowhani A. Deep sequencing analysis of RNAs from a grapevine showing Syrah decline symptoms reveals a multiple virus infection that includes a novel virus. Virology. 2009;387:395-401. DOI 10.1016/j.virol.2009.02.028.

Takahashi H., Fukuhara T., Kitazawa H., Kormelink R. Virus Latency and the Impact on Plants. Front Microbiol. 2019;10:2764. DOI 10.3389/fmicb.2019.02764.

Visvader J.E., Symons R.H. Eleven new sequence variants of citrus exocortis viroid and the correlation of sequence with pathogenicity. Nucleic Acids Res. 1985;13:2907-2920. DOI 10.1093/nar/13.8.2907.

Wu Q., Ding S-W., Zhang Y., Zhu S. Identification of viruses and viroids by next-generation sequencing and homology-dependent and homol- ogy- independent algorithms. Annu. Rev. Phytopathol. 2015;53:425444. DOI 10.1146/annurev-phyto-080614-120030.

Wu Q., Wang Y., Cao M., Pantaleo V., Burgyan J. Homology-independent discovery of replicating pathogenic circular RNAs by deep sequencing and a new computational algorithm. Proc. Natl. Acad. Sci. USA. 2012;109:3938-3943. DOI 10.1073/pnas.1117815109

Xia C., Li S., HouW., Fan Z., Xiao H, Lu M., Sano T., Zhang Z. Global transcriptomic changes induced by infection of cucumber (Cucumis sativus L.) with mild and severe variants of hop stunt viroid. Front. Microbiol. 2017;8:2427. DOI 10.3389/fmicb.2017.02427.

Zhang Z., Qi S., Tang N., Zhang X., Chen S., Zhu P., Ma L., Cheng J., Xu Y., Lu M., Discovery of replicating circular RNAs by RNA-seq and computational algorithms. PLoS Pathog. 2014;10:e1004553. DOI 10.1371/ journal.ppat.1004553.

Zheng Y., Gao S., Padmanabhan C., Li R., Galvez M., Gutierrez D., Fuentes S., Ling K.-S., Kreuze J., Fei Z. VirusDetect: An automated pipeline for efficient virus discovery using deep sequencing of small RNAs. Virology. 2017;500:130-138. DOI 10.1016/j.virol.2016.10.017.

Zheng Y., Wang Y., Ding B., Fei Z. Comprehensive transcriptome analyses reveal that potato spindletuber Viroid triggers genome-wide changes in alternative splicing, inducible trans-acting activity of phased secondary small interfering RNAs, and immune responses. J. Virol. 2017;91(11):e00247-17. DOI 10.1128/JVI.00247-17.

Конфликт интересов. Автор заявляет об отсутствии конфликта интересов.

Поступила в редакцию 18.11.2020. После доработки 15.12.2020. Принята к публикации 17.12.2020. 